\title{
Saudi Consensus for Low-Premixed Insulin Analogues in Type 2 Diabetes: Consensus Report
}

\author{
Abdulrahman Alshaikh', Mohammed Aljamal'2, Saud Alsifri' ${ }^{3}$, Ali Alrumaih", Samia Bokhari ${ }^{5}$, \\ Mohammed Almuzaini', Khalid Alyahya', Abdulaziz Bin Shaikh4, Turky Alharbi', \\ Rashid Aljuwair ${ }^{8}$, Fahad Alsabaan ${ }^{9}$, Emad R. Issak ${ }^{10}$;it
}

\footnotetext{
${ }^{1}$ Medicine Department, College of Medicine, King Abdulaziz University, Jeddah, KSA

${ }^{2}$ Supply Chain Department, King Fahd Armed Forces Hospital, Jeddah, KSA

${ }^{3}$ Endocrinology Department, Alhada \& Taif Armed Forces Hospitals, Taif, KSA

${ }^{4}$ Pharmaceutical Care Department, Medical Services Directorate, Riyadh, KSA

${ }^{5}$ Endocrinology Department, King Fahad Armed Forces Hospital, Jeddah, KSA

${ }^{6}$ Pharmacy Department, Prince Sultan Military Medical City, Riyadh, KSA

${ }^{7}$ Family Medicine Department, Prince Sultan military Medical City, Riyadh, KSA

${ }^{8}$ Endocrinology Department, Dahran Medical Complex, Dahran, KSA

${ }^{9}$ Endocrinology Department, Security Forces Hospital, Riyadh, KSA

${ }^{10}$ Medicine Department, Faculty of Medicine, Ain-Shams University, Cairo, Egypt

Email: *dr.emad.r.h.issak@gmail.com
}

How to cite this paper: Alshaikh, A. Aljamal, M., Alsifri, S., Alrumaih, A., Bokhari, S., Almuzaini, M., Alyahya, K, Shaikh, A.B., Alharbi, T., Aljuwair, R., Alsabaan, F. and Issak, E.R. (2021) Saudi Consensus for Low-Premixed Insulin Analogues in Type 2 Diabetes: Consensus Report. International Journal of Clinical Medicine, 12, 165-182. https://doi.org/10.4236/ijcm.2021.124016

Received: March 13, 2021

Accepted: April 26, 2021

Published: April 29, 2021

Copyright (๑) 2021 by author(s) and Scientific Research Publishing Inc. This work is licensed under the Creative Commons Attribution International License (CC BY 4.0).

http://creativecommons.org/licenses/by/4.0/ (c) (i) Open Access

\begin{abstract}
We learned from the literature that premixed insulins are short-acting insulin or rapid-acting insulin analogue mixed with intermediate-acting insulin in a fixed ratio, addressing FBG and PPBG in one injection. There are two categories; high-mix and low-mix premixed insulins. We, a Saudi task force, gathered to develop an explicit, evidence-based consensus for the use of the low-mix premixed insulin for better glycemic control. The treatment with premixed aspart 30 was non-inferior to treatment with premixed insulin lispro 25. In addition, Self-monitored blood glucose levels were comparable. Safety profiles were similar between both treatments, as was the incidence of hypoglycemic episodes. The switch between both products of the low-mix family can be carried out without any problem. Both products of the low-mix premixed insulin analogues aspart 30/70 and premixed insulin lispro 25/75 have comparable efficacy and safety as shown from the medical literature. Therefore, we can change from one to another safely as demonstrated by the US FDA statement. In addition, the ergonomic features of KwikPen's design and function may offer important advantages for the user during insulin administration.
\end{abstract}




\section{Keywords}

Low-Mix, Premixed Insulin, Lispro 25/75, Aspart 30/70

\section{Introduction}

According to the International Diabetes Federation (IDF) Diabetes Atlas, the worldwide prevalence of diabetes mellitus (DM) is expected to become $9.9 \%$ by the year 2045 with a total number of 629 Million [1]. It is associated with significant morbidity and mortality across the globe. Its prevalence is rising rapidly in Saudi Arabia [2]. To address both the fasting blood glucose (FBG) and post-prandial blood glucose (PPBG), the premix insulin formulations provide a combination of both rapid/short-acting and intermediate/long-acting insulins in a fixed ratio, in a single injection. There are two categories; high-mix and low-mix premixed insulins. We, a Saudi task force, gathered to develop an explicit, evidence-based consensus for the use of the low-mix premixed insulin for better glycemic control. This article has the recommendations of this expert panel.

\subsection{Premixed Insulins}

Premixed insulins are short-acting insulin or rapid-acting insulin analogue mixed with intermediate-acting insulin in a fixed ratio, addressing FBG and PPBG in one injection. They are listed hereunder in Table 1.

They have some advantages over the self-mixed insulin. These advantages include accurate dosage, efficacy, and patient convenience. All can be translated into increased compliance and better long-term control of DM [3] [4].

\subsection{Pharmacokinetics of Insulin Analogues}

The pharmacokinetics of medication includes several parameters: the absorption, the distribution, the metabolism, and the elimination. Insulin absorption is

Table 1. Premixed insulins.

\begin{tabular}{cccc}
\hline Insulin Type & Trade Name & Onset of Action & Duration of Action \\
\hline $\begin{array}{c}\text { Premixed } \\
\text { Human regular/NPH } \\
\text { Premixed analogues }\end{array}$ & Human Mixtard 30/70 & Variable & Variable \\
High-mix & & & \\
Lispro/lispro protamine & Humalog Mix 50/50 & Variable & Variable \\
Aspart/aspart protamine & NovoMix 50/50 & Variable & Variable \\
Low-mix & & & \\
Lispro/lispro protamine & Humalog Mix 25/75 & Variable & Variable \\
Aspart/aspart protamine & NovoMix 30/70 & Variable & Variable
\end{tabular}


derived principally by measuring the concentration of circulating insulin over time from the start of subcutaneous injection. That can be evaluated by the euglycemic clamp technique in both normal subjects and diabetic patients (type 1 and 2 diabetes). The measures can provide a comprehensive description of the way in which the body processes the insulin from administration to elimination. Typically, the concentrations of insulin should increase or decrease by an increase or decrease in the administered dose. In addition, insulin concentration curve over time should coincide with the wanted glycemic lowering profile. Therefore, for the rapid-acting insulin analogues, the concentration of insulin should peak very quickly after the injection and be rapidly metabolized, and eliminated. The currently available rapid-acting insulins have duration of action of 3 - 5 hours according to the injected dose. Meanwhile, the concentration of the long-acting insulin analogues needs to be stable and uniform. In addition, it should be noted that current basal insulin analogues have a waning insulin concentration that may not accommodate for the morning increase in the need for insulin to cover what is called the dawn phenomenon; the transitory increase in insulin resistance in the morning [5] [6] [7].

As for the premixed insulin analogues (biphasic), the perfect profile is the combination of both a rapid-onset and peak insulin action following the injection. That is to cover the postprandial needs, followed by a rapid return to a long plateau to cover the basal needs. Current formulations of premixed biphasic insulins are not ideal in this respect (Figure 1) [5] [8] [9].

The rapid-acting insulin analogues' profiles simulate the normal physiological insulin secretion in response to meals better than the regular human insulin, with a faster onset and higher maximal concentration. However, the profiles of long-acting insulin analogues are not wholly flat and do not remain steady over the day. Premixed insulin analogues show more rapid absorption relative to premixed human insulin and have different peak concentrations in relation to the dose of the soluble rapid-acting component. The return to basal insulin levels is slow and uneven. This part of the biphasic insulin profile is known as the

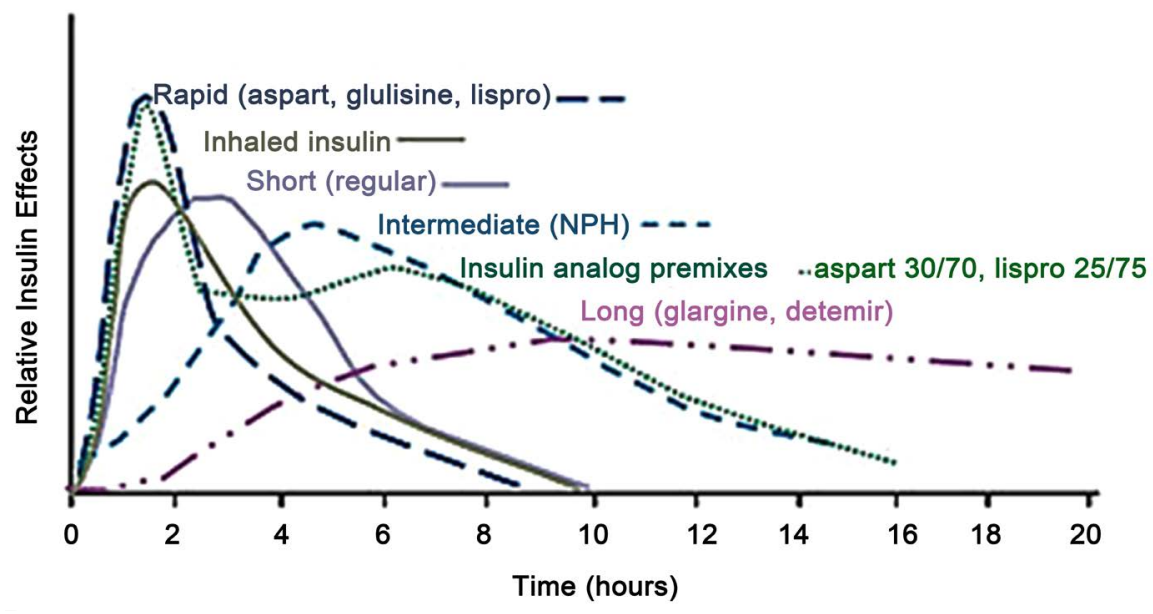

Figure 1. Representative rime action profiles of selected insulins [8] [9]. 
shoulder, which occurs due to the interaction between soluble and protaminated insulin molecules [10] [11] [12] [13] [14].

\subsection{Pharmacodynamics}

The pharmacodynamic insulin profile is alike to the pharmacokinetic profile in shape. For the rapid-acting insulin analogues, it is a rapid onset and offset, and for long-acting insulin analogues, it is a long, flat, and constant profile. In a clamp study, the blood glucose levels of the subjects are kept within a certain range by infusing IV glucose. The amount of infused glucose to maintain the blood levels depicts the amount of its uptake into the cells due to activation of insulin receptors. This is called the glucose infusion rate (GIR) [5] [15].

The kinetics and dynamics of rapid-acting insulin analogues (aspart and lisporo) are similar, as shown in Figure 2 [16].

Glucose lowering effect from published pharmacodynamics studies conducted in patients with T2DM as measured by the glucose infusion rate (GIR) for insulin aspart $(0.3 \mathrm{U} / \mathrm{kg})$ [17], human soluble insulin $(0.3 \mathrm{U} / \mathrm{kg})$ [17], biphasic insulin aspart 30/70 (0.6 U/kg) [11], biphasic human insulin $30(0.6 \mathrm{U} / \mathrm{kg})$ [11], insulin detemir $(0.8 \mathrm{U} / \mathrm{kg})$ [10] and insulin glargine $(0.8 \mathrm{U} / \mathrm{kg})$ [10]. All insulin preparations were administered at time $=0 \mathrm{~h}$. In those patients, both insulin aspart and insulin lispro given just before meals, have reduced the rise of the 2-h PPBG by an $18 \%$ - $48 \%$ reduction compared to human insulin given 30 -min before meal time [12] [18] [19] [20].

Cross-over trials showed that the pharmacodynamics of insulin lispro mix 25 [21] [22] have a lower peak rise in BG compared with premixed human insulin and NPH. In addition, premixed insulin aspart 30 had 44 and 34\% lower PPBG concentrations compared with premixed human insulin 30 after breakfast and dinner, respectively [23]. In addition, these results are consistent with the differences between rapid-acting insulin analogues and human insulin [5].

Moreover, for those requiring higher doses of rapid-acting insulin, there is good evidence showing the relative increases in early PPBG utilization with the high-mix insulin analogues (e.g., premixed insulin aspart 50/50 and 70/30, and

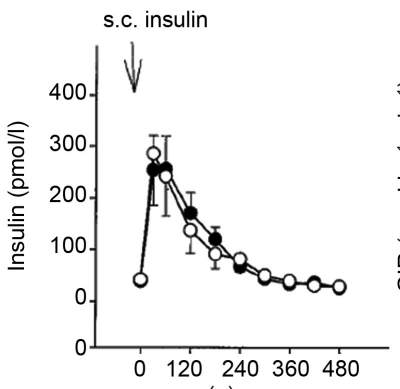

(a)

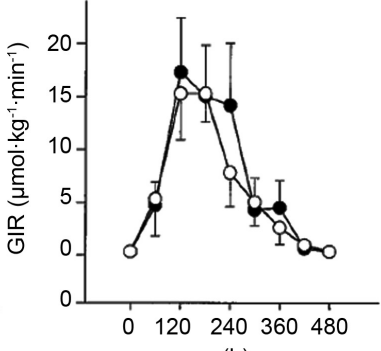

(b)



(c)

Figure 2. Insulin aspart and insulin lispro: (a): Serum insulin levels before and after subcutaneous injection (at $0 \mathrm{~min}$ ) of insulin aspart or insulin lispro. (b): GIR is needed to prevent hypoglycemia in the same patients. (c): Plasma glucose concentrations before and after subcutaneous injection of insulin aspart or insulin lispro in the same patients [16]. 
premixed insulin lispro 50/50 and 75/25) [24] [25] [26].

Insulin analogues provide physicians the ability to more closely mimic the normal physiology of insulin and to select different regimens depending on patient preferences and lifestyle. Faster onset of action of rapid-acting insulin analogues has improved postprandial glycemic control in patients with T2DM; and more predictable glycemic lowering profiles of the insulin analogues have also led to reductions in reported nocturnal hypoglycemia, particularly comparing long-acting insulin analogues with NPH [5] [12] [13] [23] [27] [28] [29] [30].

Finally, whilst premixed insulin analogues have been shown to be associated with a lower incidence of nocturnal hypoglycemia compared with premixed human insulin and help in the intensification of insulin therapy, the protaminated/precipitated component does not provide the same duration of action or profile of physiological basal insulin replacement. In essence, premixed insulin is a mixture of rapid and intermediate-acting insulin, that is, carrying the same limitations as the individual components. Unfortunately, neither insulin glargine nor insulin detemir is suitable for mixing with other insulin analogues as this mixing substantially alters their pharmacokinetic properties.

In summary, premixed insulin analogues do not have two distinct peaks. Once absorbed, the time of action corresponds to the rapid onset of action of the rapid-acting component, and the duration of action corresponds to the intermediate insulin component. The peak of action of the premixed insulin analogues is unimodal (one distinct peak), corresponding to the maximum effect of the rapid-acting component, and it is steep with a gradual decline. The rapid absorption is because of the rapid-acting component and this rapid pronounced onset of action signifies that these analogues can be utilized immediately before or following a meal [11] [25] [31] [32] [33].

\subsection{Clinical Utility}

It is not clear who could most benefit from the utilization of the premixed insulin analogues. However, based on data from one meta-analysis (Giugliano et al., 2011) [34] and the DURABLE study [35], it can be concluded that that certain people with DM could benefit more by starting an insulin treatment with this type of therapy. Those categories of patients who have $\mathrm{HbAlc}$ around $8.5 \%$ have higher elevations in PPBG are less willing to carry out several SMBG measurements throughout the day [35]. Whereas the low-mix 25 could be suitable for those patients who have not reached adequate PPBG levels [36] [37] [38], the high-mix 50/50 can enhance the premixed insulin therapy and is good for those who are already using premixed analogues [39].

The premixed insulin analogues 50/50 can also be an option for those using the basal insulin in addition to multiple doses of rapid-acting insulin but are not compliant with the regimen of therapy [40] [41]. In addition, these higher premixed insulins could be an initial choice of therapy for those needing higher daily doses of rapid-acting insulins or those who eat a high carbohydrate meal. [39] [42] [43]. 
It is well established that people with T2DM who do not achieve glycemic targets despite the lifestyle modifications, and use of one or more oral antidiabetic drugs (OADs) should start insulin therapy [44] [45]. The type of insulin used in the initial phase depends on the insulin resistance degree and the quantity of consumed food at each meal [33] [46] [47]. Moreover, recent evidence suggests that the low-mix premixed insulin analogues 25 provides a similar glycemic control to that of insulin glargine plus lispro in insulin-naïve people with uncontrolled DM on OADs. Non-inferiority of the low-mix regimen 25 was shown in such category of patients [48].

Once the doctors have opted for one of the low-mix premixed insulin analogues, either the aspart $30 / 70$ or lispro $25 / 75$, insulin can be given at the start at a dose of $0.1 \mathrm{U} / \mathrm{kg}$ before breakfast. Then, the dose can be titrated or repeated before dinner on the following days, depending on individual needs [5]. This titration is based on the BG levels pre-meals. Insulin is to be adjusted every three days, according to the average BG levels at the respective times [49]. If HbA1c is not at targets at four months after the initiation of insulin despite an appropriate BG levels before meals, then PPBG should be evaluated [25]. For those patients already on the basal insulin therapy who may not achieve the HbA1c targets due to high PPBG levels despite good fasting levels, the premixed insulin analogues can be used. The total dose of the premixed insulin analogues per day could be given on a 1:1 ration (the same total daily dose). Half the dose is to be given before the breakfast and the other half before the dinner [49].

\subsection{Are All the Low-Mix Premixed Insulin Analogues the Same?}

In a randomized, multinational, open-label, company sponsored (Novo Nordisk) crossover comparison study of premixed insulin aspart 30 and premixed insulin lispro 25 in adult patients with T2DM, Niskanen et al. (2004) compared their efficacy and safety profiles. The premixed insulin aspart 30 (30\% soluble insulin aspart and $70 \%$ protaminated insulin aspart) and the premixed insulin lispro 25 (25\% soluble insulin lispro and 75\% neutral protamine lispro were used in a BID injection regimen in patients with T2DM. In addition, they assessed the patients' preference for pen devices. Glycemic control was assessed by measuring the $\mathrm{HbA1c}$ after three months of treatment [50].

A total of 151 patients with T2DM were screened. Inclusion required insulin treatment for the past six months, total daily insulin dose $<1.80 \mathrm{IU} / \mathrm{kg}$, age more than 18 years, $\mathrm{HbA} 1 \mathrm{c}<12 \%$, and body mass index $<35 \mathrm{~kg} / \mathrm{m}^{2}$. Patients had to be eligible for BID mixed insulin treatment and be able and willing to perform SMBG. Previous therapy with insulin analogues or the use of OADs within the last month was not allowed. Furthermore, those cases with abnormal renal, hepatic, or cardiac functions were excluded. Also, other exclusion criteria included severe uncontrolled hypertension, allergy to the trial medications, pregnancy, or drug or alcohol abuse. Nine patients did not fulfill the inclusion or exclusion criteria, and five decided to withdraw before randomization. Randomization was 
carried out using an interactive voice response system. The investigator telephoned the system and obtained the treatment sequence from the underlying randomization codes, thereby ascertaining unbiased treatment allocation in the open-label trial design [50].

\section{Efficacy Assessments}

Glycemic control was assessed by the measurement of HbA1c after 12 weeks of treatment. In addition, short-term glycemic control was assessed by SMBG measurements. OneTouch ${ }^{\circledast}$ Profile $^{\circledast}$ BG meter (LifeScan, Inc., Milpitas, California) were used. Patients were asked to perform a seven-point BG profile on any day in the week prior to the start and end of treatment periods [50].

\section{Safety Assessments}

Adverse events (AEs) and hypoglycemic episodes were recorded throughout the trial. The investigator classified the AEs as serious or non-serious and assessed the severity of the events. AEs were considered serious if they resulted in death, a life-threatening experience, inpatient hospitalization or prolongation of hospitalization, persistent or significant disability/incapacity, or congenital anomaly/birth defect. All AEs not fulfilling the above definition were classified as non-serious. AE severity was assessed as mild, moderate, or severe. Relation to the trial product was assessed by the investigator as probable, possible, unlikely, or impossible to assess. Hypoglycemic episodes were classified as major (requiring third-party assistance), minor (BG reading $<2.8 \mathrm{mmol} / \mathrm{L}$ with or without symptoms of hypoglycemia), or symptoms of hypoglycemia (not confirmed by BG reading). Vital signs (pulse and blood pressure, sitting) were recorded at the beginning and end of each treatment period. Measurements were taken after patients had been resting in a chair for 5 minutes [50].

\section{Preference for Pen Device}

Patient satisfaction with the pen devices was assessed using two device-specific questionnaires: 1 for the FlexPen and 1 for the Humalog Pen, differing by the device names only. The questionnaires included 16 questions aimed at assessing features of the pens that were related to ease of use, utility and convenience, and confidence in correct diabetes management. In addition, patients were asked to state whether they had experienced any problems using the pens and if so, they were asked to describe them. Each questionnaire was completed at the end of the treatment period in which the patients had used the particular device. The questionnaires were completed by the patients at the clinic before the clinical consultation. While completing the questionnaires, patients were left alone, but with access to a staff member if questions arose. If uncertain about specific questions, the patient was asked to read the question again and answer in the most appropriate way. The patients placed the questionnaire in an envelope and sealed it. At the end of the second treatment period, patients rated the importance of the 
features assessed in the device-specific questionnaires. Furthermore, after having used both pen devices, patients' overall pen preference was evaluated using a comparative questionnaire. The patients were asked which pen they found easiest to use and which they would prefer to continue using [50].

\section{Characteristics of the Participants}

A total of 137 patients were randomized to treatment. Four of the randomized patients were withdrawn during the run-in treatment with biphasic human insulin 30: 1because of an AE and three for other reasons. The mean (SD) characteristics of the remaining 133 patients (79 men, 54 women) exposed to the premixed insulin aspart 30 (Asp 30) and/or the premixed insulin lispro 25 (Lisp25) were as follows: age, 62.3 (9.2) years; body mass index, $28.1(3.9) \mathrm{kg} / \mathrm{m}^{2}$; and HbA1c, $8.5 \%$ (1.1). The mean duration of diagnosed T2DM was 12.1 (7.1) years (range, 0.6 - 35.8 years). Concomitant illnesses included symptoms related to late T2DM complications. A total of 129 patients completed the trial; four patients withdrew during the first treatment period (two because of AEs considered to be unlikely related to trial products [one receiving Asp 30 and 1 receiving Lisp25], one owing to ineffective therapy (Lisp25), and 1 for other reasons [Asp 30]) [50].

\section{Glycemic Control}

A total of 132 patients were exposed to Asp 30 and/or Lisp25 and had evaluable efficacy data, thus fulfilling the criteria of the ITT population. Treatment with Asp 30 was non-inferior to treatment with Lisp25 (Table 2). No carryover effects between treatments were indicated. Overall, a mean reduction in HbAlc of $\sim 0.5 \%$ from baseline to the end of the second treatment period was observed. The BG levels at each of the seven-time points of the BG profiles were comparable (Table 2). The BG analyses were made without adjustment for baseline

Table 2. Glycemic control with biphasic insulin aspart 30 (30\% soluble insulin aspart and $70 \%$ protaminated insulin aspart [Asp30]) and biphasic insulin lispro 25 (25\% soluble insulin lispro and 75\% neutral protamine lispro [lisp25]) as assessed by HbA1c and BG levels after 12 weeks of BID treatment [50].

\begin{tabular}{cccccc}
\hline & $\begin{array}{c}\text { Asp 30, } \\
\text { mean }\end{array}$ & $\begin{array}{c}\text { Lisp25, } \\
\text { mean }\end{array}$ & $\begin{array}{c}\text { Asp 30 - Lisp25, } \\
\text { mean }\end{array}$ & CI & $P$ \\
\hline HbA1c\% & 8.15 & 8.01 & 0.14 & 0.008 to 0.275 & 0.082 \\
BG, mmol & & & & & \\
Breakfast & 7.6 & 7.5 & 0.2 & -0.3 to 0.6 & 0.422 \\
90 min after breakfast & 9.5 & 9.7 & -0.2 & -1.0 to 0.5 & 0.524 \\
Lunch & 6.5 & 6.8 & -0.4 & -0.9 to 0.2 & 0.168 \\
90 min after lunch & 9.7 & 9.8 & -0.1 & -0.7 to 0.5 & 0.746 \\
Dinner & 8.7 & 8.6 & 0.1 & -0.5 to 0.7 & 0.824 \\
90 min after dinner & 9.6 & 10.0 & -0.4 & -1.1 to 0.2 & 0.186 \\
Bedtime & 8.6 & 8.9 & -0.4 & -1.1 to 0.3 & 0.291 \\
\hline
\end{tabular}


values; however, such an adjustment did not significantly alter the results. Before lunch, BG was particularly well controlled with both products $(6.5 \mathrm{mmol} / \mathrm{L}$ with Asp 30 and $6.8 \mathrm{mmol} / \mathrm{L}$ with Lisp25). Mean BG was also within the recommended range at the other time points, except before dinner and at bedtime, when the BG target was slightly exceeded. Mean daily insulin doses increased slightly during the overall 24-week treatment period: from $0.65 \mathrm{U} / \mathrm{kg}$ to 0.67 $\mathrm{U} / \mathrm{kg}$ for patients randomized to the Asp 30/Lisp25 sequence and from 0.67 $\mathrm{U} / \mathrm{kg}$ to $0.71 \mathrm{U} / \mathrm{kg}$ for patients in the Lisp25/Asp 30 sequence [50].

\section{Safety}

The safety population included all 133 exposed patients. The incidence of AEs was similar for both Asp 30 (83 events) and lisp25 (68 events). Upper respiratory tract infections and influenza-like symptoms were the most frequently reported AEs (reported by $>5 \%$ of patients). Fourteen AEs were serious (11 for Asp 30 and 3 for lisp25); none were judged to be related to trial products. Most AEs were mild (Asp 30: 61.4\%; lisp25: 70.6\%) or moderate (Asp 30: 33.7\%; lisp25: 26.5\%) in severity. There was $1 \mathrm{AE}$ withdrawal: a 71-year-old man who was treated for 79 days with Mix 25 was diagnosed with malignant neoplasm considered unlikely to be related to treatment. After withdrawal, the patient suffered an acute myocardial infarction and died. The six AEs considered possibly or probably related to trial products were mild and non-serious (Asp 30: 4 events [headaches (2), injection site bruising, and bruising from a fall during a hypoglycemic episode]; lisp25: 2 events [injection site bruising]). During the two 12-week treatment periods, two major hypoglycemic episodes were reported, one for Asp 30 and 1 for lisp25. Fifty-seven patients receiving Asp 30 had 269 minor or symptoms-only hypoglycemic episodes, and 53 patients receiving lisp25 had 233 episodes. Of these minor and symptoms only episodes, 101 episodes with Asp 30 and 79 episodes with lisp25 occurred during the initial four weeks of treatment. These episodes were not included in the statistical analysis. The rate of minor and symptoms-only episodes during the last eight weeks of treatment was 0.69 episode/mo of exposure for Asp 30 and 0.62 episode/mo of exposure for lisp25. As the estimated Asp 30/lisp25 ratio of episodes did not differ significantly from $1(P=0.292)$, the risk was comparable. For vital signs, four patients had systolic blood pressure findings slightly and transiently $>180 \mathrm{~mm}$ $\mathrm{Hg}$. In conclusion, the safety profiles were considered similar for the two treatments [50].

\section{Patients' Preference for Pen Device}

The device-specific questionnaires assessed features of the pens related to their ease of use, utility and convenience, and to patients' confidence in the correct management of their diabetes (e.g., confidence in setting, controlling, and injecting the correct dose). Analyses of the questionnaire results were performed on the safety population; however, owing to incomplete answers, the exact 
number of patients in each crossover analysis was lower (between 111 and 118). Patients were consistently more satisfied with the FlexPen than with the Huma$\log$ Pen, with statistically significantly higher scores given to the FlexPen for all 16-device features assessed in the device-specific questionnaires (Table 3; all $P<$ 0.005). For example, of the 118 patients having answered question 1 in both questionnaires, 63 (53.4\%) gave the FlexPen favorably higher scores than the Humalog Pen, whereas 3 (2.5\%) patients rated the Humalog Pen higher than the FlexPen. The remaining $52(44.1 \%)$ patients gave equal scores to the two devices [50].

Table 3. Comparison of patients' assessments of the NovoMix ${ }^{\circledast} 30$ FlexPen $^{\star \star}$ (FlexPen) and the Humalog ${ }^{\otimes}$ Mix $25^{\text {Tn† }}$ Pen (Humalog Pen) using the device-specific questionnaires [50].

\begin{tabular}{|c|c|c|c|c|}
\hline & \multicolumn{4}{|c|}{ No. (\%) of observations in favor of } \\
\hline & $\begin{array}{l}\text { No. of Paired } \\
\text { Observations }\end{array}$ & FlexPen & $\begin{array}{l}\text { Humalog } \\
\text { Pen }\end{array}$ & $\mathrm{P}$ \\
\hline 1) How easy/difficult is to read the dose scale? & 118 & $63(53.4)$ & $3(2.5)$ & $<0.001$ \\
\hline $\begin{array}{l}\text { 2) How difficult do you find it to hold the pen stable } \\
\text { when injecting insulin? }\end{array}$ & 118 & $48(401.7)$ & $14(11.9)$ & $<0.001$ \\
\hline $\begin{array}{l}\text { 3) How easy/difficult is to hear the clicks for each } \\
\text { unit increment? }\end{array}$ & 118 & $61(51.7)$ & $9(7.6)$ & $<0.001$ \\
\hline $\begin{array}{l}\text { 4) How easy/difficult is to feel the clicks for each } \\
\text { unit increment? }\end{array}$ & 118 & $58(49.2)$ & $8(6.8)$ & $<0.001$ \\
\hline $\begin{array}{l}\text { 5) How easy/difficult is to push down the injection } \\
\text { button? }\end{array}$ & 118 & $62(52.5)$ & $14(11.9)$ & $<0.001$ \\
\hline $\begin{array}{l}\text { 6) How easy/difficult is to turn the dose selector } \\
\text { when choosing the right dose? }\end{array}$ & 117 & $53(45.3)$ & $3(2.6)$ & $<0.001$ \\
\hline $\begin{array}{l}\text { 7) How easy/difficult is to know if the push } \\
\text { button has been pushed completely down }\end{array}$ & 117 & $64(54.7)$ & $9(7.7)$ & $<0.001$ \\
\hline $\begin{array}{l}\text { 8) How easy/difficult is to see the dose scale } \\
\text { when injecting? }\end{array}$ & 117 & $75(64.1)$ & $10(8.5)$ & $<0.001$ \\
\hline $\begin{array}{l}\text { 9) How confident are you that you set the insulin } \\
\text { dose correctly every time? }\end{array}$ & 117 & $42(35.9)$ & $10(8.5)$ & $<0.001$ \\
\hline $\begin{array}{l}\text { 10) How confident are you that you inject the } \\
\text { correct amount of insulin every time? }\end{array}$ & 117 & $47(40.2)$ & $11(9.4)$ & $<0.001$ \\
\hline $\begin{array}{l}\text { 11) Overall, how confident are you in your } \\
\text { management of your daily insulin injections } \\
\text { using this pen? }\end{array}$ & 113 & $54(47.8)$ & $8(7.1)$ & $<0.001$ \\
\hline $\begin{array}{l}\text { 12) Overall, how confident are you in controlling } \\
\text { your blood sugar level using this pen? }\end{array}$ & 113 & $39(34.5)$ & $17(15.0)$ & $<0.005$ \\
\hline 13) How suitable is the pen to use in public? & 112 & $51(45.5)$ & $19(17.0)$ & $<0.001$ \\
\hline $\begin{array}{l}\text { 14) How confident are you that the air shot } \\
\text { has been done correctly? }\end{array}$ & 111 & $40(36.0)$ & $11(9.9)$ & $<0.001$ \\
\hline 15) How convenient do you find the size of the pen? & 113 & $64(56.6)$ & $6(5.3)$ & $<0.001$ \\
\hline $\begin{array}{l}\text { 16) How comfortable do you find the handling } \\
\text { of the pen (eg, is it easy to hold, does it fit } \\
\text { nicely in the hand, etc)? }\end{array}$ & 113 & $66(58.4)$ & $13(11.5)$ & $<0.001$ \\
\hline
\end{tabular}


Users were asked to rate the importance of the individual feature of the pen to ensure that the questions dealt with features were relevant for the patients. All were of great significance, as the rating "very/ rather important" was given by $80 \%$ to $99 \%$ of patients, depending on the actual feature. For example, $96.0 \%$ of patients believed that it was "very/rather important" that the dose scale was easy to read (question 1). Regarding this feature, $99.2 \%$ of patients answered that they found the dose scale of the FlexPen "very/fairly easy to read," whereas $68.5 \%$ gave this assessment to the Humalog Pen [50].

When asked if they had experienced any problems using the pens, $32.4 \%$ answered that they had experienced problems with the Humalog Pen, and $9.0 \%$ had experienced problems with the FlexPen $(P<0.001)$. The most frequently reported problems with the FlexPen were various kinds of injection difficulties (8 patients). For the Humalog Pen, this type of problem was also the most frequently reported (23 patients). In addition, several patients found it difficult to read the dose scale of the Humalog Pen (nine patients), and concern was expressed as to whether the correct dose had been injected using this pen (seven patients) [50].

Patients were asked about their pen preference in the comparative questionnaire, completed at the end of the second treatment period (Figure 3). For overall ease of use, $73.6 \%$ preferred the FlexPen, whereas 9.1\% preferred the Huma$\log$ Pen $(P<0.001)$. The remaining $16.5 \%$ and $0.8 \%$ of patients found the devices equally easy or equally difficult to use, respectively. In addition, $74.6 \%$ preferred to continue using the FlexPen, and 14.3\% favored the Humalog Pen $(P<0.001)$. The remaining $7.1 \%$ and $4.0 \%$ of patients preferred either or neither device, respectively [50].

Before entering this trial, $\sim 78 \%$ of patients had used a device from Novo Nordisk A/S, 14\% a device from Eli Lilly and Company/Becton, Dickinson and Company (Eli Lilly/BD) (Eli Lilly devices are produced by BD), 7\% a vial and syringe, and $1 \%$ a device from other manufacturers. When evaluating pen preference for these groups separately, the results were similar to those of the entire population. Hence, of the Novo Nordisk A/S device users, $73.5 \%$ preferred to
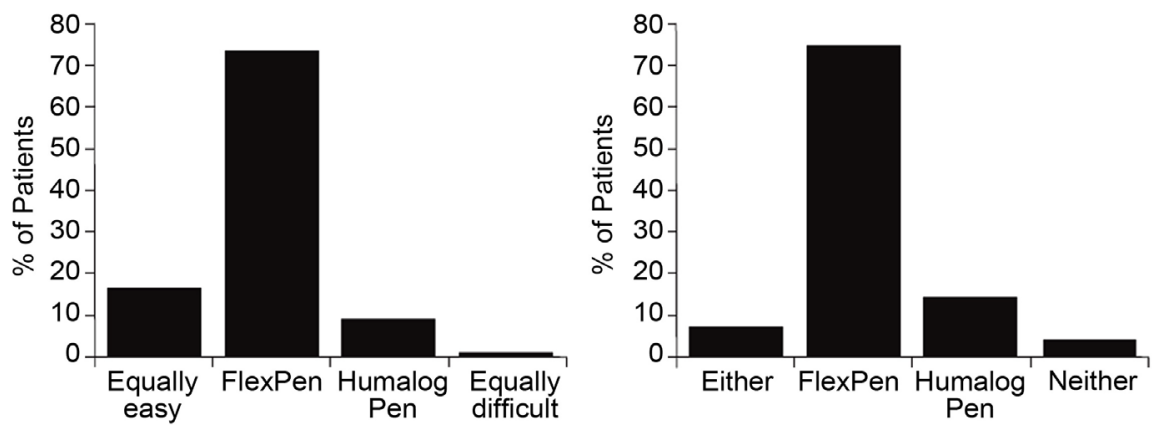

Figure 3. Patients' preference for pen device assessed using the comparative questionnaire. FlexPen vs Humalog Pen, $\mathrm{P}<0.001$. FlexPen $=$ NovoMix $^{\circledast} 30$ FlexPen $^{\circledast}$ (Novo Nordisk A/S, Bagsværd, Denmark); Humalog Pen $=$ Humalog ${ }^{\circledR}$ Mix $25^{\mathrm{Tm}}$ Pen (Eli Lilly and Company, Indianapolis, Indiana) [50]. 
continue using the FlexPen and $17.4 \%$ the Humalog Pen. Of the Eli Lilly/BD device users, $73.7 \%$ preferred to continue using the FlexPen and 5.3\% the Humalog Pen [50].

Preference for a particular device might be influenced by previous experience; for example, patients might choose a pen from the manufacturer of their previous pen. When patients were grouped by previous pen manufacturer (Novo Nordisk A/S or Eli Lilly/BD), the pen preference in the 2 groups was similar. Hence, of the Novo Nordisk pen users, $73.5 \%$ would prefer to continue using the FlexPen and $17.4 \%$ the Humalog Pen; of the Eli Lilly/BD users, $73.7 \%$ would prefer to continue using the FlexPen and 5.3\% the Humalog Pen. Thus, a predetermined preference for pens produced by the patients' previous pen manufacturer was not demonstrated [50].

\section{Summary}

The results of this study showed that treatment with premixed aspart 30 was non-inferior to treatment with premixed insulin lispro 25. In addition, Selfmonitored blood glucose (SMBG) levels were comparable. Safety profiles were similar between both treatments, as was the incidence of hypoglycemic episodes [50].

Moreover, the switch between both products of the low-mix family can be carried out without any problem. The US FDA stated that, in emergency conditions, one insulin mix product might be substituted for another on a unitper-unit basis [51].

Preference for a particular device might be influenced by the previous experience of the patients. Thus, the results of the previous study of Niskanen et al. (2004) were not conclusive as regards this item. Hereunder, we will present some different views from other studies related to the device evaluation. Ignaut et al., 2008 in their study, evaluated the ergonomic features and injection force, as measured by the glide force (GF), the glide force variability (GFV) for the new Humalog $^{\oplus}$ Mix75/25 KwikPen $^{\text {Tx }}$ (KwikPen), and compared with the NovoLog ${ }^{\circledast}$ Mix 70/30 FlexPen ${ }^{\circledast}$ (FlexPen). Fifty prefilled insulin pen devices (25 of each type) were measured for diameter at the cartridge holder and dose window, length and weight with cap attached, and thumb reach at 30 and 60 units. GF was also determined for 100 devices (50 of each type); GFV at 30 and 60 unit doses was calculated for the plateau portion of the force curve based on the minimum and maximum force measured in that portion of the curve [52]. The results of this study showed that, while FlexPen was lighter in weight than KwikPen, and presented a slightly smaller diameter at the cartridge holder and dose window, KwikPen had a shorter overall pen length compared to FlexPen, with a shorter thumb reach at both the 30- and 60-unit dose settings. The maximum GF for KwikPen was less than FlexPen. KwikPen GFV was lower across both doses. They concluded that while FlexPen was lighter with a slightly smaller cartridge holder and dose window diameter, KwikPen was shorter in length with 
less thumb reach than FlexPen. KwikPen also demonstrated lower GF and GFV, resulting in a smoother injection profile than FlexPen. These features of KwikPen's design and function may offer important advantages for the user during insulin administration [52].

In another simulated injection study by Ignaut et al. (2009) showed patients' preference for Humalog KwikPen to the vial and syringe and FlexPen. Huma$\log$ KwikPen was found to be easy-to-use, easy-to-hold while injecting, and easy-to-press the injection button. Accurate dose measurements were reported with Humalog KwikPen more than with vial and syringe. Feature comparison of Humalog KwikPen to vial and syringe found the pen device preferable to vial and syringe in all attributes compared. A pen device may offer greater patient acceptance of insulin therapy and improved treatment satisfaction. These findings may be clinically beneficial because health gains may be obtained through increased adherence and enhanced diabetes self-management. The advantages of pen devices used in this study should be considered by health care providers in consultation with patients regarding diabetes treatment options [53].

A third study was a randomized, open-label, two-period, eight-sequence crossover study in insulin pen-naïve patients with DM was carried out by Clark et al. (2010) to determine the patient ease-of-use and preference for the Humalog KwikPenversus the next generation FlexPen. The results of this study showed that among pen-naïve patients with DM who had a preference, the majority preferred the insulin lispro pen over the insulin aspart pen with regard to ease-of-use [54].

\section{Recommendations}

- Both products of the low-mix premixed insulin analogues aspart 30/70 and premixed insulin lispro 25/75 have comparable efficacy and safety as shown from the medical literature. Therefore, we can change from one to another safely as demonstrated by the US FDA statement.

- In addition, the ergonomic features of KwikPen's design and function may offer important advantages for the user during insulin administration.

\section{Conflicts of Interest}

The authors declare no conflicts of interest regarding the publication of this paper.

\section{References}

[1] International Diabetes Federation (2017) IDF Diabetes Atlas. 8th Edition, International Diabetes Federation, Brussels. http://www.diabetesatlas.org

[2] Al Dawish, M.A., Robert, A.A., Braham, R., Al Hayek, A.A., Al Saeed, A., Ahmed, R.A., et al. (2016) Diabetes Mellitus in Saudi Arabia: A Review of the Recent Literature. Current Diabetes Reviews, 12, 359-368. https://doi.org/10.2174/1573399811666150724095130

[3] Turner, H. and Matthews, D. (2000) The Use of Fixed-Mixture Insulins in Clinical 
Practice. European Journal of Clinical Pharmacology, 56, 19-25. https://doi.org/10.1007/s002280050715

[4] Frias, P.F. and Frias, J.P. (2017) New Basal Insulins: A Clinical Perspective of Their Use in the Treatment of Type 2 Diabetes and Novel Treatment Options beyond Basal Insulin. Current Diabetes Reports, 17, 91.

https://doi.org/10.1007/s11892-017-0926-8

[5] Evans, M., Schumm-Draeger, P.M., Vora, J. and King, A.B. (2011) A Review of Modern Insulin Analogue Pharmacokinetic and Pharmacodynamic Profiles in Type 2 Diabetes: Improvements and Limitations. Diabetes, Obesity and Metabolism, 13, 677-684. https://doi.org/10.1111/j.1463-1326.2011.01395.x

[6] Sheldon, B., Russell-Jones, D. and Wright, J. (2009) Insulin Analogues: An Example of Applied Medical Science. Diabetes, Obesity and Metabolism, 11, 5-19. https://doi.org/10.1111/j.1463-1326.2008.01015.x

[7] Edelman, S.V., Bode, B.W., Bailey, T.S., et al. (2010) Insulin Pump Therapy in Patients with Type 2 Diabetes Safely Improved Glycemic Control Using a Simple Insulin Dosing Regimen. Diabetes Technology \& Therapeutics, 12, 627-633. https://doi.org/10.1089/dia.2010.0034

[8] Brunton, S., Carmichael, B., et al. (2005) Type 2 Diabetes: The Role of Insulin. The Journal of Family Practice, 54, 445-451.

[9] Rave, K., Bott, S., et al. (2005) Time-Action Profile of Inhaled Insulin in Comparison with Subcutaneously Injected Insulin Lispro and Regular Human Insulin. Diabetes Care, 28, 1077-1082. https://doi.org/10.2337/diacare.28.5.1077

[10] Hompesch, M., Ocheltree, S.M., Wondmagegnehu, E.T., et al. (2009) Pharmacokinetics and Pharmacodynamics of Insulin Lispro Protamine Suspension Compared with Insulin Glargine and Insulin Detemir in Type 2 Diabetes. Current Medical Research and Opinion, 25, 2679-2687. https://doi.org/10.1185/03007990903223739

[11] Heise, T., Heinemann, L., Hovelmann, U., et al. (2009) Biphasic Insulin Aspart 30/70: Pharmacokinetics and Pharmacodynamics Compared with Once-Daily Biphasic Human Insulin and Basal-Bolus Therapy. Diabetes Care, 32, 1431-1433. https://doi.org/10.2337/dc09-0097

[12] Rosenfalck, A.M., Thorsby, P., Kjems, L., et al. (2000) Improved Postprandial Glycaemic Control with Insulin Aspart in Type 2 Diabetic Patients Treated with Insulin. Acta Diabetologica, 37, 41-46. https://doi.org/10.1007/s005920070034

[13] Hermansen, K., Vaaler, S., Madsbad, S., et al. (2002) Postprandial Glycemic Control with Biphasic Insulin Aspart in Patients with Type 1 Diabetes. Metabolism, 51, 896-900. https://doi.org/10.1053/meta.2002.33358

[14] Luzio, S., Dunseath, G., Peter, R., Pauvaday, V. and Owens, D.R. (2006) Comparison of the Pharmacokinetics and Pharmacodynamics of Biphasic Insulin Aspart and Insulin Glargine in People with Type 2 Diabetes. Diabetologia, 49, 1163-1168. https://doi.org/10.1007/s00125-006-0243-2

[15] DeFronzo, R.A., Tobin, J.D. and Andres, R. (1979) Glucose Clamp Technique: A Method for Quantifying Insulin Secretion and Resistance. American Journal of Physiology, 237, E214-E223. https://doi.org/10.1152/ajpendo.1979.237.3.E214

[16] Homko, C., Deluzio, A., Jimenez, C., Kolaczynski, J.W. and Boden, G. (2003) Comparison of Insulin Aspart and Lispro: Pharmacokinetic and Metabolic Effects. Diabetes Care, 26, 2027-2031. https://doi.org/10.2337/diacare.26.7.2027

[17] Krones, R., Schutte, C. and Heise, T. (2009) The Rapid-Acting Properties of Insulin Aspart Are Preserved in Elderly People with Type 2 Diabetes. Diabetes, Obesity and Metabolism, 11, 41-44. https://doi.org/10.1111/j.1463-1326.2008.00988.x 
[18] Anderson, J.H., Brunelle, R.L., Koivisto, V., Trautmann, M.E., Vignati, L. and DiMarchi, R. (1997) Improved Mealtime Treatment of Diabetes Mellitus Using an Insulin Analogue. Multicenter Insulin Lispro Study Group. Clinical Therapeutics, 19, 62-72. https://doi.org/10.1016/S0149-2918(97)80073-2

[19] Perriello, G., Pampanelli, S., Porcellati, F., et al. (2005) Insulin Aspart Improves Meal Time Glycaemic Control in Patients with Type 2 Diabetes: A Randomized, Stratified, Double-Blind and Cross-Over Trial. Diabetic Medicine, 22, 606-611. https://doi.org/10.1111/j.1464-5491.2005.01473.x

[20] Luzio, S., Peter, R., Dunseath, G.J., Mustafa, L. and Owens, D.R. (2008) A Comparison of Preprandial Insulin Glulisine versus Insulin Lispro in People with Type 2 Diabetes over a 12-h Period. Diabetes Research and Clinical Practice, 79, 269-275. https://doi.org/10.1016/j.diabres.2007.11.013

[21] Malone, J.K., Yang, H., Woodworth, J.R., et al. (2000) Humalog Mix25 Offers Better Mealtime Glycemic Control in Patients with Type 1 or Type 2 Diabetes. Diabetes \& Metabolism, 26, 481-487.

[22] Koivisto, V.A., Tuominen, J.A. and Ebeling, P. (1999) Lispro Mix25 Insulin as Premeal Therapy in Type 2 Diabetic Patients. Diabetes Care, 22, 459-462. https://doi.org/10.2337/diacare.22.3.459

[23] McSorley, P.T., Bell, P.M., Jacobsen, L.V., Kristensen, A. and Lindholm, A. (2002) Twice-Daily Biphasic Insulin Aspart 30 versus Biphasic Human Insulin 30: A Double-Blind Crossover Study in Adults with Type 2 Diabetes Mellitus. Clinical Therapeutics, 24, 530-539. https://doi.org/10.1016/S0149-2918(02)85129-3

[24] Heise, T., Eckers, U., Kanc, K., Nielsen, J.N. and Nosek, L. (2008) The Pharmacokinetic and Pharmacodynamic Properties of Different Formulations of Biphasic Insulin Aspart: A Randomized, Glucose Clamp, Crossover Study. Diabetes Technology \& Therapeutics, 10, 479-485. https://doi.org/10.1089/dia.2008.0019

[25] Hirao, K., Maeda, H., Urata, S., et al. (2007) Comparison of the Pharmacokinetic and Pharmacodynamic Profiles of Biphasic Insulin Aspart 50 and 30 in Patients with Type 2 Diabetes Mellitus: A Single-Center, Randomized, Double-Blind, TwoPeriod, Crossover Trial in Japan. Clinical Therapeutics, 29, 927-934. https://doi.org/10.1016/j.clinthera.2007.05.017

[26] Chen, J.W., Lauritzen, T., Christiansen, J.J., Jensen, L.H., Clausen, W.H. and Christiansen, J.S. (2005) Pharmacokinetic Profiles of Biphasic Insulin Aspart 30/70 and 70/30 in Patients with Type 1 Diabetes: A Randomized Double-Blinded Crossover Study. Diabetic Medicine, 22, 273-277. https://doi.org/10.1111/j.1464-5491.2004.01404.x

[27] Parkner, T., Dyrskog, S.E., Laursen, T., et al. (2010) Obesity Does Not Influence the Unique Pharmacological Properties of Different Biphasic Insulin Aspart Preparations in Patients with Type 2 Diabetes. Diabetes, Obesity and Metabolism, 12, 414-420. https://doi.org/10.1111/j.1463-1326.2009.01178.x

[28] Malone, J.K., Woodworth, J.R., Arora, V., et al. (2000) Improved Postprandial Glycemic Control with Humalog Mix75/25 after a Standard Test Meal in Patients with Type 2 Diabetes Mellitus. Clinical Therapeutics, 22, 222-230. https://doi.org/10.1016/S0149-2918(00)88480-5

[29] Bretzel, R.G., Arnolds, S., Medding, J. and Linn, T. (2004) A Direct Efficacy and Safety Comparison of Insulin Aspart, Human Soluble Insulin, and Human Premix Insulin (70/30) in Patients with Type 2 Diabetes. Diabetes Care, 27, 1023-1027. https://doi.org/10.2337/diacare.27.5.1023

[30] Roach, P., Yue, L. and Arora, V. (1999) Improved Postprandial Glycemic Control 
during Treatment with Humalog Mix25, a Novel Protamine-Based Insulin Lispro Formulation. Humalog Mix25 Study Group. Diabetes Care, 22, 1258-1261. https://doi.org/10.2337/diacare.22.8.1258

[31] Tambascia, M.A., Nery, M., Gross, J.L., Ermetice, M.N. and de Oliveira, C.P. (2013) Evidence-Based Clinical Use of Insulin Premixtures. Diabetology \& Metabolic Syndrome, 5, Article No. 50. https://doi.org/10.1186/1758-5996-5-50 https://dmsjournal.biomedcentral.com/articles/10.1186/1758-5996-5-50

[32] Liebl, A., Prusty, V., Valensi, P., Kawamori, R., Christiansen, J.S., Palmer, A.J., Balschmidt, P., Ligthelm, R. and Mohan, V. (2012) Ten Years of Experience with Biphasic Insulin Aspart 30: From Drug Development to the Latest Clinical Findings. Drugs, 72, 1495-1520. https://doi.org/10.2165/11635490-000000000-00000

[33] Sociedade Brasileira de Diabetes: Algoritmo para o tratamento do Diabetes Tipo 2-Atualização 2011-Posicionamento Oficial SBD no 3.

[34] Giugliano, D., Maiorino, M.I., Bellastella, G., Chiodini, P., Ceriello, A. and Esposito, K. (2011) Efficacy of Insulin Analogs in Achieving the Hemoglobin A1c Target of < 7\% in Type 2 Diabetes: Meta-Analysis of Randomized Controlled Trials. Diabetes Care, 34, 510-517. https://doi.org/10.2337/dc10-1710

[35] Buse, J.B., Wolffenbuttel, B.H., Herman, W.H., Hippler, S., Martin, S.A., Jiang, H.H., Shenouda, S.K. and Fahrbach, J.L. (2011) The DURAbility of Basal versus Lispro Mix 75/25 Insulin Efficacy (DURABLE) Trial: Comparing the Durability of Lispro Mix 75/25 and Glargine. Diabetes Care, 34, 249-255.

https://doi.org/10.2337/dc10-1701

[36] Malone, J.K., Bai, S., Campaigne, B.N., Reviriego, J. and Augendre-Ferrante, B. (2005) Twice Daily Pre-Mixed Insulin Rather than Basal Insulin Therapy Alone Results in Better Overall Glycaemic Control in Patients with Type 2 Diabetes. Diabetic Medicine, 22, 374-381. https://doi.org/10.1111/j.1464-5491.2005.01511.x

[37] Landó, L.F., Massari, F., Oviedo, A. and Jiang, H. (2012) Régimen con insulina lispro mix 25 versus insulina glargina para la diabetes tipo 2. Medicina (Buenos Aires), 72, 235-242.

[38] Malone, J.K., Kerr, L.F., Campaigne, B.N., Sachson, R.A. and Holcombe, J.H. (2004) Combined Therapy with Insulin Lispro Mix 75/25 plus Metformin or Insulin Glargine plus Metformin: A 16-Week, Randomized, Open-Label, Crossover Study in Patients with Type 2 Diabetes Beginning Insulin Therapy. Clinical Therapeutics, 26, 2034-2044. https://doi.org/10.1016/j.clinthera.2004.12.015

[39] Roach, P., Arora, V., Campaigne, B.N., Mattoo, V. and Rangwala, S. (2003) Huma$\log$ Mix50 before Carbohydrate-Rich Meals in Type 2 Diabetes Mellitus. Diabetes, Obesity and Metabolism, 5, 311-316. https://doi.org/10.1046/j.1463-1326.2003.00277.x

[40] Rosenstock, J., Ahmann, A.J., Colon, G., Scism-Bacon, J., Jiang, H. and Martin, S. (2008) Advancing Insulin Therapy in Type 2 Diabetes Previously Treated with Glargine plus Oral Agents: Prandial Premixed (Insulin Lispro Protamine Suspension/Lispro) versus Basal/Bolus (Glargine/Lispro) Therapy. Diabetes Care, 31, 20-25. https://doi.org/10.2337/dc07-1122

[41] Robbins, D.C., Beisswenger, P.J., Ceriello, A., Goldberg, R.B., Moses, R.G., Pagkalos, E.M., Milicevic, Z., Jones, C.A., Sarwat, S. and Tan, M.H. (2007) Mealtime 50/50 Basal + Prandial Insulin Analogue Mixture with a Basal Insulin Analogue, Both plus Metformin, in the Achievement of Target HbAlc and Pre- and Postprandial Blood Glucose Levels in Patients with Type 2 Diabetes: A Multinational, 24-Week, Randomized, Open-Label, Parallel-Group Comparison. Clinical Therapeutics, 29, 
2349-2364. https://doi.org/10.1016/j.clinthera.2007.11.016

[42] Jacober, S.J., Scism-Bacon, J.L. and Zagar, A.J. (2006) A Comparison of Intensive Mixture Therapy with Basal Insulin Therapy in Insulin-Naive Patients with Type 2 Diabetes Receiving oral Antidiabetes Agents. Diabetes, Obesity and Metabolism, 8, 448-455. https://doi.org/10.1111/j.1463-1326.2006.00605.x

[43] Robbins, D.C., Beisswenger, P.J., Moses, R.G., Ceriello, A., Milicevic, Z., Sarwat, S., Jones, C.A. and Tan, M.H. (2006) Comparison of Insulin Lispro Mid Mixture (MM) plus Metformin (Met) with Glargine (G) plus Met on HbA1c (A1C) and Blood Glucose (BG) Profiles in Patients with Type 2 Diabetes [Abstract]. Diabetologia, 49, 603-604.

[44] Inzucchi, S.E., Bergenstal, R.M., Buse, J.B., Diamant, M., Ferrannini, E., Nauck, M., Peters, A.L., Tsapas, A., Wender, R. and Matthews, D.R. (2012) Management of Hyperglycaemia in Type 2 Diabetes: A Patient-Centered Approach. Position Statement of the American Diabetes Association (ADA) and the European Association for the Study of Diabetes (EASD). Diabetologia, 55, 1577-1596.

https://doi.org/10.1007/s00125-012-2534-0

[45] Ismail-Beigi, F., Moghissi, E., Tiktin, M., Hirsch, I.B., Inzucchi, S.E. and Genuth, S. (2011) Individualizing Glycemic Targets in Type 2 Diabetes Mellitus: Implications of Recent Clinical Trials. Annals of Internal Medicine, 154, 554-559. https://doi.org/10.7326/0003-4819-154-8-201104190-00007

[46] American Diabetes Association (2012) Standards of Medical Care in Diabetes-2012. Diabetes Care, 35, S11-S63. https://doi.org/10.2337/dc12-s011

[47] Handelsman, Y., et al. (2011) American Association of Clinical Endocrinologists Medical Guidelines for Clinical Practice for Developing a Diabetes Mellitus Comprehensive Care Plan. Endocrine Practice, 17, 1-53.

https://pubmed.ncbi.nlm.nih.gov/21474420/

[48] Bowering, K., Reed, V.A., Felicio, J., Landry, J., Ji, L. and Oliveira, J. (2012) A Study Comparing Insulin Lispro Mix 25 with Glargine plus Lispro Therapy in Patients with Type 2 Diabetes Who Have Inadequate Glycaemic Control on Oral Antihyperglycaemic Medication: Results of the PARADIGM Study. Diabetic Medicine, 29, e263-e272. https://doi.org/10.1111/j.1464-5491.2012.03722.x

[49] Hirsch, I.B., Bergenstal, R.M., Parkin, C.G., Wright, E. and Buse, J.B. (2005) A Real-World Approach to Insulin Therapy in Primary Care Practice. Clinical Diabetes, 23, 78-86. https://doi.org/10.2337/diaclin.23.2.78

[50] Niskanen, L., Jensen, L.E., Råstam, J., Nygaard-Pedersen, L., Erichsen, K. and Vora, J.P. (2004) Randomized, Multinational, Open-Label, 2-Period, Crossover Comparison of Biphasic Insulin Aspart 30 and Biphasic Insulin Lispro 25 and Pen Devices in Adult Patients with Type 2 Diabetes Mellitus. Clinical Therapeutics, 26, 531-540. https://doi.org/10.1016/S0149-2918(04)90055-0

[51] Research C for DE (2018) Information Regarding Insulin Storage and Switching between Products in an Emergency. FDA [Internet]. https://www.fda.gov/drugs/emergency-preparedness-drugs/information-regarding-i nsulin-storage-and-switching-between-products-emergency

[52] Ignaut, D.A., Opincar, M. and Lenox, S. (2008) FlexPen ${ }^{\circledR}$ and KwikPenTM Prefilled Insulin Devices: A Laboratory Evaluation of Ergonomic and Injection Force Characteristics. Journal of Diabetes Science and Technology, 2, 533-537. https://doi.org/10.1177/193229680800200327

[53] Ignaut, D.A., Schwartz, S.L., Sarwat, S. and Murphy, H.L. (2009) Comparative Device Assessments: Humalog KwikPen Compared with Vial and Syringe and Flex- 
Pen. Diabetes Education, 35, 789-798.

https://doi.org/10.1177/0145721709340056

[54] Clark, P.E., Valentine, V., Bodie, J.N. and Sarwat, S. (2010) Ease of Use and Patient Preference Injection Simulation Study Comparing Two Prefilled Insulin Pens. Current Medical Research and Opinion, 26, 1745-1753.

https://doi.org/10.1185/03007995.2010.489028 